\title{
Presentació del monogràfic. Tuitar, postejar, bloguejar: ciberactivismes feministes contra violències sexistes per la pau i la igualtat
}

\author{
Coordinat per \\ Ana M. González Ramos \\ UNIVERSIDAD PABLO DE OLAVIDE \\ Verònica Gisbert-Gracia \\ UNIVERSITAT DE VALÈNCIA
}

Les eines digitals han inaugurat una nova era per als moviments socials (Castells, 2012; Rovira, 2017), la lluita dels col-lectius organitzats en favor de la defensa dels seus drets, la igualtat i la salvaguarda dels drets humans. En el camp dels feminismes, el hacktivisme, concepte que designa l'activisme a través de les xarxes socials, persegueix a consciència la violència de gènere i l'assetjament que pateixen, sobretot, les dones i les persones menors d'edat. Les eines digitals connecten la societat civil, l'articulen i difonen els missatges per demanar atenció i exigir-ne una reparació (Dean i Aune, 2015; Friedman, 2015; Chamberlain, 2017). En un món global i connectat a partir de molts trets en comú i distincions a causa de les diverses situacions de desigualtat i violències estructurals (Massey, 1994; Sassen, 2007, 2015), les xarxes socials i la seua agilitat de comunicació amenacen la contextualització, l'experiència situada i l'empatia de qui acumula un posicionament condicionat per la relacionalitat interseccionada (Haraway, 1988; Creswley, 1989; Collins, 2000).

La mobilització social internacional ha sigut una constant des dels primers tractats internacionals - el Tractat de Roma o la Conferència de Pequín, entre d'altres-, però cobra més força en l'era de la globalització. D’una banda, les qüestions locals són exposades més fàcilment per la societat civil mobilitzada; de l'altra, la ciutadania global té coneixement de qualsevol situació de violència succeïda a qualsevol racó del món. En conseqüència, l'una i l'altra poden aliar-se per a generar onades d'indignació i pressionar els poders públics perquè reparen la situació. Aquest mecanisme de mobilització s'ha activat moltes vegades en les últimes dècades, particularment en defensa de drets humans fonamentals i com a resposta a la necessitat d'organitzar-se contra les violències estructurals (amb cibercampanyes que van des del \#MeToo fins al \#YoSoy123, passant per \#BringBackOurGirls, \#OccupyWallStreet, \#BlackLivesMatter...). Les tecnologies de la informació i la comunicació, i en especial les xarxes socials, canalitzen les demandes de la població civil i proporcionen múscul a les revoltes ciutadanes.

Si bé la interseccionalitat és un instrument teòric i polític fonamental per a la construcció del coneixement científic i per a l'articulació de l'activisme polític, també pressuposa un repte intel-lectual. I és que caldria plantejar-se preguntes com ara: poden les 
experiències situades, fruit de les coordenades locals socioculturals, tindre un efecte de translació global? Es perden matisos importants de l'element polític local en la translació cap a la mobilització internacional? Hi ha aspectes que se simplifiquen o que es malinterpreten? Inclús quan s'aconsegueix l'adhesió massiva i la protesta unànime, ¿quins efectes produeixen? Quins processos de canvi s'activen? I quan la situació és d'extrema complexitat política com, per exemple, en contextos socials marcats per conflictes armats i de convivència en situacions de violència extrema (Bunch, 2001; Friedman, 2005; Magallón, 2010, 2012; Bloom, 2011; Leatherman, 2014; Anderlini, 2018), ¿quines conseqüències poden derivar-se'n? Cal preguntar-se si les cibercampanyes són liderades per agències internacionals o per líders locals, i en qualsevol cas, ¿quins efectes tenen sobre l'agenda política local, sobre la resolució del conflicte i sobre la quotidianitat de les persones locals? També caldria valorar si expressen el sentiment d'un dels grups de pressió en conflicte o si tenen en compte la complexitat del problema i el sentiment global de la població (Hooks, 1986; Mohanty, 1984, 1991; Khoja-Moolji, 2015; Maxfield, 2016).

Aquestes qüestions constitueixen la base de la nostra proposta d'investigació, que té el seu origen en el projecte d'investigació «Les xarxes socials com a eina de lluita contra les violències de gènere» (2017, RICIP0000), finançat per l'Institut Català Internacional per la Pau (ICIP). Alguns dels articles ací reunits estan relacionats amb aquesta investigació, com és el cas dels articles de Carmen Magallón, Beatriz RevellesBenavente i Maite García, així com el de les editores d'aquest número especial de la revista Debats. Amb motiu de la finalització d'aquest projecte es va dur a terme el seminari «Paz y Derechos Humanos: \#enREDadas en la lucha contra las violencias de género», cofinançat per l'Instituto de la Mujer. El monogràfic que teniu a les mans culmina el treball proposat en aquest projecte, a saber, establir una xarxa d'investigació amb les persones dedicades a aquest àmbit del coneixement. Per a aconseguir-ho, de febrer a abril de 2019 vam establir un període de recepció de treballs per a completar aquest monogràfic i difondre el treball internacional elaborat per altres investigadores en aquest àmbit científic. La participació va ser molt satisfactòria i ens va permetre sumar-hi articles i punts de vista diferents sobre els ciberactivismes més recents des 
d'una perspectiva de gènere i de promoció d'un espai lliure de violències sexistes. A aquesta xarxa les editores hi afegírem altres investigadores de l'àrea com a revisores externes, que en aquell moment en van fer una avaluació cega, però que no per això han de quedar en l'anonimat. Agraïm el seu temps i l'excel-lent treball a Patricia Peña (Universidad de Chile), Jessie Bustillo (London Metropolitan University), Lola S. Almendros (Centre Superior d'Investigacions Científiques, CSIC), Sandra Martínez Domingo (Institut Català Internacional per la Pau, ICIP), Nataly Buslon (Barcelona Supercomputer Center, BSC), Josemira Reis (Universidade Federal da Bahia), Raquel Vañó (Universitat de València), Elisa García-Mingo (Universidad Complutense de Madrid), Esther Torrado Martín-Palomino (Universidad de La Laguna), Mónica Paz (Universidade Federal da Bahia), Gabriela Loureiro (University of West London), Kemly Camacho (Sulá Batsú, Costa Rica).

El monogràfic està format per sis articles, més altres materials de què parlarem a continuació. En primer lloc, Carmen Magallón, en «L'extremisme violent: un repte per al feminisme pacifista», planteja el rol de les dones en les societats violentes, del reconeixement com a subjectes víctimes i de l'agenda política internacional que comença a establir marcs de protecció per al paper de les dones com a constructores de pau. En les seues pròpies paraules, «líders destacades del feminisme pacifista estan passant de la crítica a la proposta de noves estratègies», i, guiades per la mirada de les dones, aporten solucions i no únicament una anàlisi sobre la violència.

L'article firmat per Ana M. González Ramos, Beatriz Revelles-Benavente i Verònica Gisbert-Gracia presenta el conflicte armat nigerià i l'objectivització del cos de les xiquetes i dones en zones de conflicte extrem. Les autores descriuen el paper complex que exerceixen les dones en una posició d'interseccionalitat en la societat nigeriana, segons els seus contextos religiosos i socioculturals.

L'article de Beatriz Revelles-Benavente, en tercer lloc, aprofundeix en l'anàlisi del paper de les xiquetes en el conflicte i la manera en què la campanya \#BringBackOurGirls va poder instrumentalitzar la mobilització política des d'una postura feminista afirmativa. L'autora assenyala l'elasticitat del concepte d'infància si el mirem des de les categories culturals imbricades en les distintes societats, i també temporalment, en el cas de Chibok, en què van ser segrestades sent xiquetes, però que ja han deixat de ser-ho.

María Teresa García-Català ha realitzat una anàlisi a partir de l'extracció de dades de l'API Twitter del període comprés entre la creació del hashtag, el 19 de maig de 2014, i el 16 de maig de 2019, a fi de comprendre les bases de l'èxit internacional d'aquesta campanya. Els resultats apunten a una verdadera campanya local amb impacte global, perquè la majoria de missatges provenen de persones de nacionalitat nigeriana, i a la importància dels esdeveniments concrets per a entendre l'activitat en les xarxes socials.

En cinqué lloc, l'article de Blessing Datiri obri la discussió sobre la manera en què les cibercampanyes contribueixen a la lluita feminista per al progrés en l'eradicació de la violència contra les dones, per la qual cosa analitza les campanyes \#BringBackOurGirls, 
\#JusticeForNoura i \#JusticeForOchanya. Aquest article respon a una de les qüestions plantejades anteriorment, que no és altra que la necessitat de contextualitzar les mobilitzacions en la realitat local i de constatar-ne l'efecte produït. En aquest cas s'analitzen les condicions masclistes i de violència domèstica suportades per les dones africanes, que han aconseguit mobilitzar i articular el moviment feminista africà amb l'objectiu d'exigir una agenda de gènere als seus països.

Finalment, Macarena Hanash Martínez presenta, des d'un altre angle, la violència patriarcal suportada per les dones feministes quan actuen en l'espai virtual, i utilitza, com a estudi de cas, l'atac del moviment Gamergate, amb Anita Sarkeesian i Zoë Quinn com a desafortunades protagonistes, produït l'agost de 2019. L'autora també mostra els moviments autoorganitzats de les pròpies activistes per a gestionar la ciberviolència «allà on les plataformes es neguen a imposar termes d'ús i servei que protegisquen col-lectius en risc de violència contra l'assetjament masclista, racista, trànsfob i homòfob».

Els documents que componen aquest número especial es complementen amb dos documents especials. En primer lloc, l'entrevista de Begonya Enguix Grau a l'activista i exministra Obiageli Ezekwesili, realitzada el 20 de setembre de 2019, en la qual ens mostra el punt de vista d'una de les persones responsables de la cibercampanya \#BringBackOurGirls. Obiageli Ezekwesili relata la manera com es va articular la campanya internacional i ens ofereix la seua valoració sobre l'èxit de la campanya i l'impacte sobre la política nacional de Nigèria. L'entrevistada emfatitza la capacitat de produir un estat general d'opinió que posa en marxa diversos recursos per a avançar en la igualtat de gènere de les xiquetes i les dones africanes. Finalment, connectant amb el tema inicial, és a dir, la cultura de la pau i el feminisme, presentem el poema de María Antonia García de León titulat «Nosotras nunca estuvimos allí».

No volem deixar de mostrar el nostre agraïment a l'advocada Fatima Imam, a la periodista Chika Oduah i a l'activista Rosa Muñiz, així com a totes les persones que han contribuït a generar un cos de coneixement, començant per les autores i revisores d'aquest monogràfic. Finalment hem de mencionar Sandra Martínez Domínguez en qualitat de tècnica de l'ICIP pel seu temps i la seua inestimable ajuda durant tot el temps que ha durat aquest projecte.

\section{REFERÈNCIES BIBLIOGRÀFIQUES}

Anderlini, S. N. (2018). Challenging Conventional Wisdom, Transforming Current Practices: A Gendered Lens on PVE, Transforming Current Practices. En B. Austin i H. J. Giessmann (ed.), Transformative Approaches to Violent Extremism. Berlin: Berghof Foundation.

Bloom, M. (2011). Bombshell: Women and Terrorists. Londres: Hurst.

Bunch, C. (2001). Women's Human Rights: The Challenges of Global Feminist and Diversity. En M. DeKoven (ed.), Feminist Locations: Global and Local, Theory and Practice. New Brunswick: Rutgers. 
Castells, M. (2012). Networks of Outrage and Hope. Londres: Cambridge Polity Press.

Crenshaw W., K. (1989). Demarginalizing the Intersection of Race and Sex: A Black Feminist Critique of Antidiscrimination Doctrine, Feminist Theory and Antiracist Politics. University of Chicago Legal Forum, 1989, article 8.

Collins, P. H. (2000). Black Feminist Thought: Knowledge, Consciousness and the Politics of Empowerment. Nova York: Routledge.

Chamberlain, P. (2017). The Feminist Fourth Wave: Affective Temporality. Palgrave MaCmillan.

Dean, J. i Aune, K. (2015). Feminism Resurgent? Mapping Contemporary Feminist Activisms in Europe. Social Movement Studies, 14(4): 375-395.

Friedman, E. J. (1995). Women's Human Rights: The Emergence of a Movement. En J. S. Peters i A. Wolper (1995), Women's Right, Human Rights (p. 18-35). Nova York: Routledge.

Friedman, E. J. (2015). The Reality of Virtual Reality: The Internet and Gender Equality Advocacy in Latin America. Latin American Politics and Society, 47, 1-34.

Haraway, D. (1988). Situated Knowledges: The Science Question in Feminism and the Privilege of Partial Perspective. Feminist Studies, 14(3), 575-599.

hooks, b. (1986). Ain't I a Woman: Black Women's Rights Feminism. Londres: Pluto Press.

Khoja-Moolji, S. (2015). Becoming an 'Intimate Publics': Exploring the Affective Intensities of Hashtag Feminism'. Feminist Media Studies, 15(2), 347-350.

Leatherman, J. L. (2014). Violencia sexual y conflictos armados (Ana i Maria Villellas, trad.). Barcelona: Edicions Bellaterra.

Magallón, C. (2010). Decidir en los procesos de paz, un derecho de hombres y mujeres. ¿Qué ha aportado la resolución 1325 del Consejo de Seguridad? Papeles de relaciones ecosociales y cambio global, 109, 45-56.

Magallón, C. (2012). Contar en el mundo. Una mirada sobre las relaciones internacionales desde las vidas de las mujeres. Madrid: Horas y horas.

Massey, D. B. (1994). Space, Place, and Gender. Minneapolis: University of Minnesota Press.

Maxfield, M. (2016). History Retweeting Itself: Imperial Feminist Appropriations of 'Bring Back Our Girls'. Feminist Media Studies, 16(5), 886-900.

Mohanty, C. T. (1984). Under Western Eyes: Feminist Scholarship and Colonial Discourses. Boundary 2, 12(3), 333-358.

Rovira, G. (2017). Activismo en red y multitudes conectadas: Comunicación y acción en la era de Internet. Barcelona: Icaria.

Sassen, S. (2007). Una sociología de la globalización. Buenos Aires: Katz Editores.

Sassen, S. (2015). Expulsiones. Buenos Aires: Katz Editores.

Segato, R. (2016). La guerra contra las mujeres. Madrid: Traficantes de sueños. 